Postgrad. med. J. (February 1967) 43, 103-113.

CURRENT SURVEYS

\title{
Metabolic myopathy
}

\author{
P. K. ThOMAS \\ M.D., B.Sc., M.R.C.P. \\ Royal Free and Royal National Orthopaedic Hospitals, and Institute of Neurology, London
}

RECENT years have witnessed a considerably in-
creased interest in disorders of muscle, resulting in
large measure from the advent of new investigative
techniques. This has led both to the clarification of
the nature of known disorders and to the definition
of new syndromes. In this review, a brief survey is
given of current knowledge concerning myopathic
disorders arising from metabolic disturbances.
Since the basis of many muscle diseases is not yet
understood, the inclusion of certain conditions and
the omission of others is to some extent arbitrary.

\section{Disorders of potassium metabolism}

Hypokalaemic and hyperkalaemic paralysis

Disturbances of potassium may have a profound effect on muscular excitability by influencing the membrane potential. The membrane is normally electrically polarized, the interior being negative with respect to the exterior, this potential difference depending upon an unequal distribution of potassium ions across the membrane. There is a high intracellular and a low extracellular concentration of potassium ions, the reverse being true of sodium. A propagated action potential involves a transient depolarization of the membrane associated with a sudden influx of sodium ions. Alteration in the extracellular concentration of potassium ions will influence the height of the resting potential of the membrane, hyperkalaemia having a depolarizing and hypokalaemia a hyperpolarizing effect. If of sufficient magnitude, both will lead to flaccid paralysis. With partial depolarization, hyperexcitability of the membrane with spontaneous or repetitive discharges may occur.

Attacks of hypokalaemic weakness are a feature of Conn's syndrome, due to excessive urinary excretion of potassium because of an aldosterone secreting adrenal tumour. Loss from renal tubular lesions or as a result of treatment by hydrochlorothiazide or other diuretics may be responsible, as may disorders of the alimentary tract in which loss of large amounts of gastro-intestinal fluids occurs. It may complicate the use of ion-exchange resins and sometimes occurs in the recovery phase of diabetic ketosis. Hyperkalaemic weakness may be encountered in renal failure where there is potassium retention or during severe diabetic ketosis.

\section{Familial periodic paralysis}

Families in which affected members suffer from recurrent episodes of muscular paralysis have been recognized for nearly a century and the fact that the weakness may be relieved by potassium has been known for almost as long. A reduction in the serum potassium level during attacks was first documented by Biemond \& Daniels in 1934. This disorder displays an autosomal dominant pattern of inheritance and usually begins in early adult life, attacks tending to become less frequent in later life and sometimes ceasing altogether. They often occur during rest after vigorous exertion or on awakening after sleep, and may be provoked by a large carbohydrate meal. Their severity is variable, ranging from mild localized weakness to a severe flaccid tetraplegia, the proximal muscles and the muscles innervated by the cranial nerves usually being spared. The episodes generally last for 6-12 hr, but after a severe attack, some weakness may persist for 1-2 days. The paralysed muscles are inexcitable to direct electrical stimulation and electrocardiographic abnormalities may be present during an attack. In some individuals, permanent myopathic weakness and wasting gradually appear, predominantly affecting the pelvic girdle and lower limb muscles.

The mechanism of the attacks is not yet understood. The plasma potassium level is usually reduced in the attacks, but weakness may occur at levels within the normal range and the reduction is not generally as great as that necessary to produce weakness in normal subjects. The paralysis is not therefore solely the result of the hypokalaemia. It is not due to hyperpolarization of the muscle membrane, as this has been observed to be normal in attacks (Shy et al., 1961 ; Creutzfeldt et al., 1963). During the episodes of weakness, the urinary excretion of potassium is reduced, potassium migrating into the muscle cells (Grob, Liljestrand \& Johns, 1957; Zierler \& Andres, 
1957). There is some evidence (McArdle, 1956) to suggest that a partial block in carbohydrate breakdown or synthesis exists, which results in the accumulation of indiffusible intermediary metabolites. This might then lead to a shift of water and potassium into the cells. From electron microscope studies (Shy et al., 1961), it has been shown that the muscle fibres in this condition may display a greatly dilated sarcoplasmic reticulum, lending some support to this suggestion. Conn \& Streeten (1960) claimed that disturbances of sodium metabolism are involved, sodium being retained during attacks, this being associated with an increased urinary excretion of aldosterone. Others have been unable to confirm this finding (Shy et al., 1961).

If the diagnosis is not made by the finding of a reduced plasma potassium level in a spontaneous attack, weakness may be provoked by the administration of a carbohydrate load, if necessary combined with insulin. Attacks are treated with the oral administration of potassium and may be reduced in frequency and severity by a low carbohydrate, high potassium diet. In those individuals where weakness occurs after sleep, a prophylactic dose of potassium at night may be effective. Poskanzer \& Kerr (1961a) have recommended the prophylactic administration of spironolactone.

\section{Periodic paralysis in hyperthyroidism}

Periodic paralysis is a rare accompaniment to thyrotoxicosis and is most often seen in young adult males. The majority of the reports of this association have been made from Japan (e.g. Okinaka et al., 1957). The attacks normally begin contemporaneously with the onset of the hyperthyroidism or shortly after, and signs of hyperthyroidism are not always obtrusive. The attacks are associated with hypokalaemia and tend to be provoked in the same way, although Engel (1961) believed that the underlying metabolic disturbance differed from that of familial periodic paralysis. There is usually no family history of periodic paralysis and the attacks cease with correction of the thyrotoxicosis.

\section{Adynamia episodica hereditaria (hyperkalaemic periodic paralysis)}

Tyler et al. (1951) described a family, the affected members of which were subject to episodes of muscular weakness in which the serum potassium level was normal, the weakness being aggravated rather than relieved by the administration of potassium. These cases were probably examples of the condition subsequently termed adynamia episodica hereditaria by Gamstorp (1956). The attacks of paralysis in this disorder, which displays an autosomal dominant pattern of inheritance, often begin during childhood and tend to subside during adult life. They are often more frequent and of shorter duration than in the hypokalaemic variety of periodic paralysis. They are precipitated by rest after exercise and exercise in the initial stage of an attack may prevent weakness developing. Attacks are not provoked by carbohydrate meals. Affected individuals may show mild persisting myotonic phenomena, with percussion myotonia of the tongue and thenar muscles and myotonic lig-lag on looking down after sustained upward gaze. Permanent myopathic weakness sometimes develops (McArdle, 1962).

The plasma potassium level is commonly raised in a severe attack, but may be normal. The urinary loss of potassium is increased, potassium probably leaking out from the muscle fibres (McArdle, 1962). Electromyography demonstrates that some muscle fibres cease to function, whereas others exhibit increased mechanical excitability and myotonic activity (Buchthal, Engbaek \& Gamstorp, 1958). The muscle membrane potential has been found to be reduced and this depolarization may account for the weakness and also the increased excitability of the muscle fibres encountered electromyographically (Creutzfeldt et al., 1963). The depolarization cannot be explained solely in terms of the hyperkalaemia since, as already mentioned, weakness occurs with plasma potassium levels within the normal range or with elevations insufficient to cause paralysis in normal subjects.

Diagnosis is achieved by the finding of an elevated plasma potassium level in a spontaneous attack or one precipitated by rest after exertion. Otherwise, potassium administration may be employed to provoke an attack. In treating this disorder, the frequency of attacks may be reduced by diuretics such as hydrochlorothiazide to promote potassium loss. McArdle (1962) has advocated the use of the carbonic anhydrase inhibitor dichlorphenamide. The administration of repeated oral doses of glucose also may help to prevent paralysis (Herman \& McDowell, 1963).

\section{Paramyotonia congenita}

In 1886, von Eulenberg described a condition in which myotonia produced by exposure to cold was associated with attacks of flaccid muscular paralysis. Magee (1963) drew attention to worsening of the myotonia on repeated muscular contraction (myotonia paradoxa) in such cases, and Hudson (1963) has commented on persisting muscular weakness and wasting in the legs. Whether this is a separate disease entity is at present uncertain, but this view has been advocated by Baxter \& Dyck (1961) and Magee (1963). On the other hand, Drager, Hammill \& Shy (1958) argued that 
the condition was inseparable from adynamia episodica hereditaria. Samaha (1965) recently concluded that although at present a separation into more than one clinical entity may be possible, the underlying biochemical defect in all the reported families probably only differs in degree.

\section{Normokalaemic periodic paralysis}

Poskanzer \& Kerr (1961b) reported a third type of periodic paralysis in which the attacks tended to be prolonged and severe and to occur most often at night. The plasma potassium level was normal during the attacks, but weakness could be provoked or worsened by potassium administration. They were relieved by sodium chloride and a combination of acetazolamide and 9- $\alpha$-fluorohydrocortisone was found to be effective in their prophylaxis. This form is possibly a variant of the hyperkalaemic type of periodic paralysis (Herman \& McDowell, 1963).

\section{Disorders of sodium metabolism}

The role of sodium ions in disorders of muscle is as yet poorly understood. Their possible implication in attacks of hypokalaemic familial periodic paralysis has already been mentioned. Sodium may also modify the effects of potassium in the hyperkalaemic form (Herman \& McDowell, 1963). The explanation of the weakness and fatiguability in Addison's disease is not certain, but these symptoms are relieved by correcting the electrolyte and water disturbances.

\section{Disorders of calcium metabolism}

Calcium ions, and to a lesser extent magnesium, are involved in stabilizing the electrical potential across the membrane of the muscle fibre, probably by influencing the rate of transfer of monovalent ions through the membrane. A reduced extracellular concentration of calcium increases the rate of transfer, thus increasing the excitability of the membrane. An increased extracellular concentration has the opposite effect. The membrane of the axons of peripheral nerve fibres is similarly affected and the carpo-pedal spasm of tetany resulting from a reduced concentration of calcium ions in the extracellular fluid is in fact due to spontaneous activity of peripheral nerve fibres.

Calcium ions enter the muscle fibres during contraction and the strength of contraction is proportional to the quantity of calcium entering per contraction (Bianchi \& Shanes, 1959). Vitamin D may play a role in its transfer across the membrane (Kodicek, 1963). It is thought that calcium ions are probably involved in the coupling process between the membrane action potential and the activation of the contractile mechanism.
A myopathic syndrome with limb girdle weakness, wasting and fatiguability seen in association with osteomalacia has now been reported on a number of occasions (e.g. Vicale, 1949 ; Shy, 1960 ; Prineas, Mason \& Henson, 1965). Although the nature of the underlying disturbances of muscle function is as yet uncertain, the weakness correlates poorly with the serum calcium level but is improved by the administration of vitamin $D$. It is therefore possibly related to an alteration in the metabolism of this vitamin. Electromyography may show myopathic changes and muscle biopsy reveal scattered atrophic fibres.

\section{Disorders of carbohydrate metabolism \\ Glycogen storage disease}

Carbohydrate is stored in muscle as glycogen, being synthesized from glucose. Glycogen yields energy by anaerobic breakdown to lactate and pyruvate via hexose and triose phosphates, pyruvate then entering the tricarboxylic acid cycle for oxidative breakdown. A number of disorders have now been described in which there is defective glycogen breakdown. Skeletal muscle is involved in $\alpha$-glucosidase deficiency (Pompe's disease, Cori type II) and in amylo-1,6-glucosidase deficiency (Forbes' disease, Cori type III), but muscular symptoms are not severe. They may give rise to hypotonic weakness and represent one cause of the 'floppy infant' syndrome.

Hereditary deficiency of myophosphorylase (McArdle's disease). McArdle (1951) drew attention to a rare disorder usually with an onset in childhood characterized by attacks of painful muscle cramp produced by exercise. Electromyographic examination showed that shortening in a muscle affected by a cramp is not associated with propagated action potentials and is therefore a physiological contracture. Subsequently cases were reported in which the attacks were accompanied by myoglobinuria (Schmid \& Mahler, 1959; Pearson, Rimer \& Mommaerts, 1961) and in whom persistent myopathic weakness and wasting developed (Schmid \& Mahler, 1959; Mellick, Mahler \& Hughes, 1962). The disease is due to a single completely recessive autosomal gene (Schmid \& Hammaker, 1961). Cases of late onset have also been described (Engel, Eyerman \& Williams, 1963).

McArdle observed that exercise, particularly ischaemic exercise, failed to give rise to the normal elevation of blood lactate and pyruvate, which pointed to a defect in glycogenolysis. It was subsequently shown that myophosphorylase, which is involved in the initial stage of glycogen breakdown, is absent (Mommaerts et al., 1959; Schmid \& Mahler, 1959). Hepatic glycogenolysis is un- 
affected. There are excessive quantities of glycogen in the muscle fibres, mainly in the intermyofibrillar space of the I band and beneath the sarcolemma (Schotland et al., 1965).

Treatment involves restricting activity within the limits of tolerance imposed by the development of muscle pain, although exercise tolerance can be improved by the administration of glucose or fructose before activity.

Reviews of this condition have recently been made by McArdle (1964) and Rowland et al. (1966).

Hereditary deficiency of phosphofructokinase. Tarui et al. (1965) have recently reported a disorder, probably due to an autosomal recessive gene, in which affected individuals have a life-long limitation of exercise tolerance, exercise giving rise to weakness and muscle pain. The blood lactate level fails to rise on ischaemic exercise and there is an accumulation of hexose monophosphates and to a lesser extent of glycogen in the muscles. There is an almost complete absence of muscle phosphofructokinase.

\section{Hereditary metabolic myopathy due to abnormal glycolysis}

Larsson et al. (1964) described an interesting disorder beginning in childhood characterized by a variably reduced ability for physical performance. At times when exercise tolerance is low, physical exertion gives rise to painful firm muscles, muscular paralysis and sometimes myoglobinuria. An autosomal recessive gene appears to be responsible. Oxygen utilization during exercise was found to be reduced and the elevation of blood lactate and pyruvate increased, suggesting abnormal glycolysis. It was postulated that excessive amounts of acid metabolites accumulated during exercise, causing damage and breakdown of the muscle fibres and consequent release of myoglobin.

\section{Diabetes mellitus}

The occasional occurrence of hyperkalaemic weakness in diabetic coma and of hypokalaemic weakness during the recovery phase has already received mention. Hyperkalaemia results from the movement of intracellular potassium into the extracellular compartment consequent upon tissue breakdown for energy production and excessive accumulation may occur if urinary loss is inadequate because of severe dehydration. During insulin treatment, potassium moves back into the cells and this, together with restoration of blood volume and pre-existing potassium depletion, may lead to hypokalaemia.

Wasting and weakness, often asymmetrical, involving mainly the proximal muscles in the lower limbs and accompanied by pain, occurs as a complication of diabetes. This syndrome may be unassociated with evidence of a sensory neuropathy and has been termed diabetic amyotrophy (Garland, 1955). It seems likely, however, that it is a form of diabetic neuropathy (Gilliatt \& Willison, 1962), although earlier a myopathic basis had been questioned. In a biopsy study, Locke, Lawrence \& Legg (1963) found atrophy of muscle fibres, but these were scattered and not grouped as in typical denervation atrophy. Nevertheless, the changes were not considered to indicate a primary myopathy, but were thought to be the result of degenerative changes in the nerve terminals.

\section{Hyperinsulinism}

A rare complication of insulin-secreting adenomas or carcinomas of the pancreatic islet cells and related to recurrent episodes of hypoglycaemia is a syndrome consisting of distal, or occasionally proximal, weakness and wasting in the limbs associated with fasciculation. This was studied by Mulder, Bastron \& Lambert (1956) and was considered probably to be the result of damage to the anterior horn cells and possibly also of the peripheral nerves. On the other hand, in the case studied by Levrat \& Brette (1948), the histological changes in the muscles suggested a primary myopathy with scattered fibre degeneration and in a biopsy from one of the cases reported by Mulder et al. (1956) the changes were not those of denervation atrophy. It is possible, therefore, that a direct effect on the muscles fibres may also take place.

\section{Disorders of protein metabolism Amyloidosis}

Although involvement of the peripheral nerves in primary amyloidosis is well documented (e.g. Chambers, Medd \& Spencer, 1958), apart from infiltration of the tongue and myocardium, involvement of muscle is less clearly recognized. However, proximal muscular weakness and wasting in the limbs may occur (Shy, 1960), histological examination showing infiltration of the connective tissue of the muscles with amyloid, especially around blood vessels. The muscles may exhibit pseudo-myotonia and sluggish relaxation of tendon reflexes similar to that seen in myxoedema. One case seen personally was accompanied by severe muscle pain.

\section{Miscellaneous disorders}

\section{Myoglobinuria}

Extensive acute destruction of muscle fibres from a variety of causes may lead to release of myoglobin and consequent myoglobinuria. This 
can follow crush injuries or infarction, or acute polymyositis. In Haff disease, muscle damage probably results from a toxic substance in contaminated fish and myoglobinuria may be caused by the venom of a sea-snake (Reid, 1961), this probably damaging the muscle fibre membrane (Meldrum \& Thompson, 1962). Other intracellular substances are also released, so that the serum creatine and muscle enzyme levels are increased As previously mentioned, myoglobinuria may occur in McArdle's syndrome.

Idiopathic paroxysmal myoglobinuria is an uncommon disorder, manifested by repeated episodes of muscle pain and weakness which may be associated with myoglobinuria. There is sometimes a family history of the same condition. Muscle biopsies in the acute stage show swelling and fragmentation of the fibres (Pearson, Beck \& Blahd, 1957). Prompt regeneration usually occurs, but in some patients, persisting myopathic weakness and wasting develop as a sequel to recurrent attacks. The disease has been separated into two types (Korein, Coddon \& Mowrey, 1959). The first is commoner in males and usually begins during adolescence or early adult life, the attacks being provoked by exercise. The second type occurs most frequently in children, the episodes tending to follow infections. Severe myoglobinuria may lead to renal damage. The cause of the condition is uncertain. Abnormal myoglobins have been postulated, but have not been demonstrated. The disorder of muscle glycolysis described by Larsson et al. (1964), which has already been discussed and which may give rise to myoglobinuria, has many features that resemble the first type of idiopathic paroxysmal myoglobinuria as defined by Korein et al. (1959).

\section{Myopathy in thyroid disorders}

Thyrotoxic myopathy. Chronic thyrotoxic myopathy was formerly considered to be a rare complication of hyperthyroidism, but studies in recent years have shown that the majority of patients with thyrotoxicosis have some degree of muscle disorder. Havard et al. (1963) found that muscle weakness was present in $80 \%$ of an unselected series, and in $8 \%$ it was the chief complaint. The weakness and wasting is usually proximal in distribution and particularly involves the shoulder girdle musculature. At times, the bulbar muscles are also involved, and Ramsay (1966) has suggested that the development of bulbar weakness gives rise to the cases that were in the past termed 'acute thyrotoxic myopathy'. In electromyographic studies, Havard et al. (1963) found myopathic abnormalities in $88 \%$ and they were found in $92 \%$ by Ramsay (1965). Muscle biopsies show lymphorrhages and a reduction in the diameter of the fibres, but otherwise the changes are inconspicuous. The cause of thyrotoxic myopathy is not known. An effect on oxidative phosphorylation has been postulated (Ramsay, 1966). Recovery occurs with treatment of the thyrotoxicosis.

Muscle abnormalities in myxoedema. Sluggish tendon reflexes are a frequent accompaniment of myxoedema, this being particularly evident for the ankle jerks. This is not the result of any alteration in the neural components of the reflex (Lambert et al., 1951), but appears to be due to a disturbance of the contractile mechanism (Lawson, 1958). Its explanation is unknown. At times, there is a generalized increase in muscle bulk, the muscles being abnormally firm in consistency. Movements tend to be sluggish and muscle pain may occur after use. The condition has been termed Hoffman's syndrome in the adult and DebréSemelaigne syndrome in cretinous children. The muscular abnormality resembles myotonia but electromyography fails to reveal myotonic discharges. These changes are corrected by treatment with thyroxine (Wilson \& Walton, 1959). A limb girdle myopathy was found in a series of patients with myxoedema reported by Aström, Kugelberg \& Müller (1961). They displayed mild proximal weakness and wasting, myopathic electromyographic abnormalities and rather indefinite histological changes in muscle biopsies. Most of the cases responded to treatment of the myxoedema.

\section{Corticosteroid myopathy}

A limb girdle myopathy resulting from the administration of cortiscosteroids, usually most severe for the muscles of the pelvic girdle, was originally reported by Perkoff et al. (1959). The disorder appears to be related to the dosage and duration of treatment and it has been suggested that steroids possessing a fluorine atom in the $9 \alpha$ position are particularly prone to give rise to this complication (Golding et al., 1961). Electromyography reveals myopathic changes. Muscle biopsies show scattered atrophic or necrotic muscle fibres (Adams, 1964). The serum creatine kinase level has been reported to be normal (Pearce, Pennington \& Walton, 1964). Recovery occurs on withdrawing the steroid treatment. Corticosteroid myopathy has been investigated in animals and a reversible segmental degeneration of muscle fibres reported (Ellis, 1956; Glaser \& Stark, 1958), with a predominant effect on 'white' muscle fibres (Smith, 1964). Its cause has not been established, but an effect on muscle phosphorylase has been suggested (Smith, 1964). Corticosteroid myopathy is presumably analogous to the limb 
girdle myopathy that may occur in Cushing's syndrome (Müller \& Kugelberg, 1959).

\section{Contractures in Addison's disease}

Patients with Addison's disease occasionally develop contractures of the legs, apparently the result of fascial and tendinous contracture rather than any myopathic abnormality (Thorn, 1949; Adams, Denny-Brown \& Pearson, 1962). The explanation is uncertain.

\section{Chloroquine myopathy}

In recent years, a reversible myopathy has been described in patients receiving chloroquine over a prolonged period (Whisnant et al., 1963). This has shown a proximal distribution, the lower limbs usually being more severely affected. Histologically, the muscles display a vacuolar change, similar to that reported in systemic lupus erythematosus by Pearson \& Yamazaki (1958). The vacuolar changes are associated with the accumulation of glycogen and it has therefore been suggested that chloroquine damages muscle by affecting enzymes involved in glycogen metabolism (Eadie \& Ferrier, 1966). Chloroquine myopathy has been studied experimentally by Smith \& O'Grady (1966). 'Red' muscle fibres are selectively affected and it is possible that chloroquine is bound by myohaemoglobin.

\section{Alcoholic myopathy}

An acute reversible myopathic syndrome occurring in chronic alcoholic subjects following a period of particularly high alcohol intake was described by Hed et al. (1962). The patients complained of severe muscular aching and tenderness. Oedema of the muscles and subcutaneous tissues was noted on examination. Slight myoglobinuria sometimes occurred. Biopsies showed degeneration and necrosis of muscle fibres and serum enzyme estimations suggested necrosis both of muscle and liver cells. Subsequently, a further syndrome was described (Ekbom et al., 1964) in which proximal weakness insidiously developed in chronic alcoholic subjects. Electromyography revealed myopathic abnormalities and muscle biopsy showed evidence of recent or previous destruction of muscle fibres. The weakness recovered on cessation of alcohol consumption.

The acute syndrome has recently been further studied by Perkoff, Hardy \& Velez-Garcia (1966) who found that the blood lactic acid failed to rise or showed a reduced elevation after ischaemic exercise. It was therefore suggested that muscle glycogenolysis is impaired. Although some of the patients with alcoholic myopathy have shown signs of neuropathy, thiamine deficiency does not appear to be responsible for the muscle damage.
Myopathy with mitochondrial abnormalities

Shy, Gonates \& Perez (1966) reported two genetically-determined childhood myopathies with abnormal mitochondria. In the first, which they termed megaconial myopathy, slowly progressive proximal weakness was present, muscle biopsies showing, on electron microscopy, giant mitochondria with several types of inclusion. This appeared to be accompanied by difficulty in handling intracellular lipid. In the second type, termed pleoconial myopathy, in addition to proximal weakness, prolonged attacks of flaccid weakness and salt craving occurred. Electron microscopy demonstrated greatly increased numbers of mitochondria only moderately increased in size. It was considered that there was some difficulty in handling intracellular cations.

\section{References}

ADAMS, R.D. (1964) In: Disorder of Voluntary Muscle (Ed. by J. N. Walton). Churchill, London.

adams, R.D., Denny-Brown, D. \& Pearson, C.M. (1962) Diseases of Muscle, 2nd ed. Harper, New York.

Astrom, K.E., Kugelberg, E. \& Muller, R. (1961) Hypothyroid myopathy. Arch. Neurol (Chic.), 5, 472.

BAxter, D.W. \& Dyck, P.J. (1961) Paramyotonia congenita. J. Can. med. Ass. 85, 113.

Bianchi, C.P. \& Shanes, A.M. (1959) Calcium influx in skeletal muscle at rest, during activity, and during potassium contracture. J. gen. Physiol. 42, 803.

Buchthal, F., Engbaek, L. \& Gamstorp, I. (1958) Paresis and hyperexcitability in adynamia episodica hereditaria. Neurology (Minneap.), 8, 347.

Chambers, R.A., Medd, W.E. \& SPEncer, H. (1958) Primary amyloidosis with special reference to involvement of the nervous system. Quart. J. Med. 27, 207.

ConN, J.W. \& Streeten, D.H.P. (1960) The Metabolic Basis of Inherited Disease (Ed. by J. B. Stanbury, J. B. Wyngaarden and D. S. Fredrickson). McGrawHill, New York.

Creutzfeld, O.D., Abbott, B.C., Fowler, W.M. \& PEARSON, C.M. (1963) Muscle membrane potentials in episodic adynamia. Electroenceph. clin. Neurophysiol. 15, 508.

Drager, G.A., Hammill, J.F. \& Shy, G.M. (1958) Paramyotonia congenita. Arch. Neurol. Psychiat. (Chic.), 80, 1.

EAdIE, M.J. \& FerRIER, T.M. (1966) Chloroquine myopathy. J. Neurol. Neurosurg. Psychiat. 29, 331.

EKboM, K., Hed, R., KirStein, L. \& Astrom, K.E. (1964) Muscular affections in chronic alcoholism. Arch. Neurol. (Chic.), 10, 449.

ELLIS, J.T. (1956) Necrosis and regeneration of skeletal muscles in cortisone-treated rabbits. Amer. J. Path. 32, 993.

ENGEL, A.G. (1961) Thyroid function and periodic paralysis. Amer. J. Med. 30, 327.

ENGEL, W.K., EYERMAN, E.L. \& Williams, H.E. (1963) Late-onset type of skeletal muscle phosphorylase deficiency. New Engl. J. Med. 268, 135.

GAMSTORP, I. (1956) Adynamia episodica hereditaria. Acta paediat. (Uppsala), Suppl. 108. 
Garland, H. (1955) Diabetic amyotrophy. Brit. med. J. ii, 1287.

Gilliatr, R.W. \& Willison, R.G. (1962) Peripheral nerve conduction in diabetic neuropathy. J. Neurol. Neurosurg. Psychiat. 25, 11.

Glaser, G.H. \& Stark, L. (1958) Excitability in experimental myopathy. 1. Measurement of refractory period; quinidine effect; cortisone myopathy. Neurology (Minneap.), 8, 640.

Golding, D.N., Murray, S.M., Pearce, E.W. \& ThOMPSON, M. (1961) Corticosteroid myopathy. Ann. phys. Med. 6, 171.

Grob, D., LILJESTRAND, A. \& JOHNS, R.J. (1957) Potassium movement in patients with familial periodic paralysis. Amer. J. Med. 23, 356.

Havard, C.W.H., Campbell, E.D.R., Ross, H.B. \& SPENCE, A.W. (1963) Electromyographic and histological findings in the muscles of patients with thyrotoxicosis. Quart. J. Med. 32, 145.

Hed, R., Lundmark, C., Fahlgren, H. \& Orell, S. (1962) Acute muscular syndrome in chronic alcoholism. Acta ried. scand. 171, 585.

HeRmaN, R.H. \& McDowell, M.K. (1963) Hyperkalaemic paralysis. Amer. J. Med. 35, 749.

HuDson, A.J. (1963) Progressive neurological disorder and myotonia congenita associated with paramyotonia. Brain, 86, 811 .

KODICEK, E. (1963) In: The Transfer of Calcium and Strontium across Biological Membranes (Ed. by R. H. Wasserman). Academic Press, New York.

KOREIN, J., CODDON, D.R. \& MOWRY, F.H. (1959) The clinical syndrome of paralytic myoglobinuria. Neurology (Minneap.), 9, 767.

LAMBERT, E.H., UNDERDAHL, L.O., BECKETT, S. \& MEDEROS, L.O. (1951) A study of the ankle jerk in myxedema. J. clin. Endocr. 11, 1186.

LARSSON, L.-E., LINDERHOLM, H., MUller, R., RINGQVIST, T. \& SORNAS, R. (1964) Hereditary metabolic myopathy with paroxysmal myoglobinuria due to abnormal glycolysis. J. Neurol. Neurosurg. Psychiat. 27, 361.

Lawson, J.D. (1958) The free Achilles reflex in hypo-thyroidism and hyperthyroidism. New Engl. J. Med. 259, 761.

LeVrat, M. \& Brette, R. (1948) Cancer langerhansien du pancréas avec hypoglycémie douleurs musculaires et myosite dégénérative d'origine métabolique. Presse méd. 56, 530.

Locke, S., LAWRENCE, D.G. \& LeGG, M.A. (1963) Diabetic amyotrophy. Amer. J. Med. 34, 775.

MCARDLe, B. (1951) Myopathy due to a defect in muscle glycogen breakdown. Clin. Sci. 10, 13.

MCARDLE, B. (1956) Familial periodic paralysis. Brit. med. Bull. 12, 226.

MCARDLE, B. (1962) Adynamia episodica hereditaria and its treatment. Brain, 85, 121.

MCARDLE, B. (1964) In: Disorders of Voluntary Muscle (Ed. by J. N. Walton). Churchill, London.

MAGEE, K.R. (1963) A study of paramyotonia congenita. Arch. Neurol. (Chic.), 8, 461.

MELDRUM, B.S. \& THOMPSON, R.H.S. (1962) The action of snake venoms on the membrane permeability of brain, muscle and red blood cells. Guy's Hosp. Rep. 111, 87.

Mellick, R.S., MaHler, R.F. \& Hughes, B.P. (1962) McArdle's syndrome: phosphorylase-deficient myopathy. Lancet, i, 1045.

Mommaerts, W.F.H.M., Illingworth, B., Pearson, C.M., Guillory, R.J. \& SERAYDARIAN, K. (1959) A functional disorder of muscle associated with the absence of phosphorylase. Proc. nat. Acad. Sci. (Wash.), 46, 791
Mulder, D.W., BAstron, J.A. \& LAMberT, E.H. (1956) Hyperinsulin neuronopathy. Neurology (Minneap.), 6, 627.

Muller, R. \& Kugelberg, E. (1959) Myopathy in Cushing's syndrome. J. Neurol. Neurosurg. Psychiat. 22, 314.

OKinaka, S., Shizume, K., IIno, S., Watanabe, A., Irie, M., Noguchi, A., Kuma, S., Kuma, K. \& Ito, T. (1957) The association of periodic paralysis and hyperthyroidism in Japan. J. clin. Endocr. 17, 1454.

PearCe, J.M.S., PenNington, R.J. \& Walton, J.N. (1964) Serum enzymes in muscle disease. II. Serum creatine kinase activity in muscular dystrophy and in other myopathic and neuropathic disorders. $J$. Neurol. Neurosurg. Psychiat. $27,96$.

Pearson, C.M., Beck, W.S. \& BlahD, W.H. (1957) Idiopathic paroxysmal myoglobinuria. Arch. intern. Med. 99, 376.

Pearson, C.M., Rimer, D.G. \& Mommaerts, W.F.H.M. (1961) A metabolic myopathy due to absence of muscle phosphorylase. Amer. J. Med. 30, 502.

Pearson, C.M. \& Yamazaki, J.N. (1958) Vacuolar myopathy in systemic lupus erythematosus. Amer. J. clin. Path. 29, 455.

Perkoff, G.T., Hardy, P. \& Velez-Garcia, E. (1966) Reversible acute muscular syndrome in chronic alcoholism. New Engl. J. Med. 274, 1277.

Perkoff, G.T., Silber, R., Tyler, F.H., Cartwright, G.E. \& WinTROBE, M.M. (1959) Studies in disorders of muscle. XII. Myopathy due to the administration of therapeutic amounts of 17-hydroxycorticosteroids. Amer. J. Med. 26, 891.

Poskanzer, D.C. \& KerR, D.N.S. (1961a) Periodic paralysis with response to spironolactone. Lancet, ii, 511.

PoSKanzer, D.C. \& KerR, D.N.S. (1961b) A third type of periodic paralysis with normokalaemia and favourable response to sodium chloride. Amer. J. Med. 31, 328.

Prineas, J.W., Mason, A.S. \& Henson, R.A. (1965) Myopathy in metabolic bone disease. Brit. med. J. i, 1034.

RAMSAY, I.D. (1965) Electromyography in thyrotoxicosis. Quart. J. Med. 34, 255

RAMSAY, I.D. (1966) Muscle dysfunction in hyperthyroidism. Lancet, ii, 931.

REID, H.A. (1961) Myoglobinuria and sea-snake-bite poisoning. Brit. med. J. i, 1284.

Rowland, L.P., Lovelace, R.E., Schotland, D.L., Araki, S. \& Carmel, P. (1966) The clinical diagnosis of McArdle's disease. Neurology (Minneap.), 16, 93.

SAмAнA, F.J. (1965) Hyperkalaemic periodic paralysis. Arch. Neurol. (Chic.), 12, 145.

SCHMID, R. \& HAMMAKER, L. (1961) Hereditary absence of muscle phosphorylase (McArdle's syndrome). New Engl. J. Med. 264, 223.

SCHMID, R. \& MAHLER, R. (1959) Chronic progressive myopathy with myoglobinuria: demonstration of a glycogenolytic defect in the muscle. J. clin. Invest. 38, 1044.

Schotland, D.L., SPIRo, D., Rowland, L.P. \& CARMEL, P. (1965) Ultrastructural studies of muscle in McArdle's disease. J. Neuropath. exp. Neurol. 24, 629.

SHY, G.M. (1960) Some metabolic and endocrinological aspects of disorders of striated muscle. Res. Publ. Ass. nerv. ment. Dis. 38, 274.

Shy, G.M., Wanko, T., Rowley, P.T. \& EnGel, A.G. (1961) Studies in familial periodic paralysis. Exp. Neurol. 3, 53. 
Shy, G.M., Gonatas, N.K. \& Perez, M. (1966) Two childhood myopathies with abnormal mitochondria. I. Megaconial myopathy. II. Pleoconial myopathy. Brain, 89, 133.

SMITH, B. (1964) Histological and histochemical changes in the muscles of rabbits given the corticosteroid triamcinolone. Neurology (Minneap.), 14, 857.

SMITH, B. \& O'Grady, F. (1966) Experimental chloroquine myopathy. J. Neurol. Neurosurg. Psychiat. 29, 255.

Tarui, S., OKuno, G., IKuRa, Y., Tanaka, T., Suda, M. \& Nishikawa, M. (1965) Phosphofructokinase deficiency in skeletal muscle. A new type of glycogenosis. Biochem. biophys. Res. Commun. 19, 517.

THORN, G.W. (1949) The Diagnosis and Treatment of Adrenal Insufficiency. Thomas, Springfield, Illinois.

TYLER, F.H., STEPHENS, F.E., GuNN, F.D. \& PERKOFF, G.T. (1951) Studies in disorders of muscle. VII. Clinical manifestations and inheritance of a type of periodic paralysis without hypopotassaemia. J. clin. Invest. 30, 492.

Vicale, C.T. (1949) The diagnostic features of a muscular syndrome resulting from hyperparathyroidism, osteomalacia resulting from renal tubular acidosis and perhaps related disorders of calcium metabolism (a type of Milkman's syndrome). Trans. Amer. neurol. Ass. (cited by G. M. Shy, in Res. Publ. Ass. nerv. ment. Dis. 38, 274).

Whisnant, J.P., EsPinosa, R.E., Kierland, R.R. \& LAMBERT, E.G. (1963) Chloroquine neuromyopathy. Proc. Mayo Clin. 38, 501.

Wilson, J. \& WALTON, J.N. (1959) The muscular manifestations of hypothyroidism. J. Neurol. Neurosurg. Psychiat. 22, 320.

ZIERLER, K.L. \& ANDRES, R. (1957) Movement of potassium into skeletal muscle during spontaneous attack in family periodic paralysis. J. clin. Invest. 36, 730 .

\title{
Herpes simplex virus infections
}

\author{
A. Melvin Ramsay \\ M.A., M.D. \\ Consultant Physician in Infectious Diseases, Royal Free Hospital ; \\ Consultant in Infectious Diseases, North West Metropolitan Hospital Board; \\ Lecturer in Infectious Diseases, University of London; \\ Lecturer and Official Examiner in Infectious Diseases, London School of Hygiene and \\ Tropical Medicine; \\ Consultant in Smallpox, Ministry of Health
}

INFECTION with herpes simplex virus is probably the commonest of all virus infections. The first attack occurs generally between the age of 1 and 5 years but may be deferred until adult life; it is usually sub-clinical or so trivial as not to justify medical attention but in $10 \%$ of cases it takes the form of acute gingivo-stomatitis. It is not sufficiently realized, however, that the virus may also be responsible for primary infection of the central nervous system, eye, skin and genital tract and that the eczematous skin is extremely vulnerable. Recurrent attacks of herpes simplex, usually taking the form of an eruption around the lips (herpes labialis) are common. These are due to reactivation of virus remaining latent in the cells of the buccal mucosa and around the mucocutaneous junction following the primary attack. A wide variety of factors predispose to reactivation including infections with organisms such as the pneumococcus or meningococcus, or by the common cold or influenza viruses, exposure to sun or cold, emotional upsets or hormonal disturbances such as menstruation.

\section{The aetiological agent}

Herpes simplex virus was successfully transmitted to the scarified cornea of the rabbit as long ago as 1912. It is also notable in that it was the first virus to be grown on the chorio-allantoic membrane of the chick embryo. It is a DNA virus with a diameter of $100-200 \mathrm{~m} \mu$ and is readily transmitted to a variety of animals including rabbit, mouse, guinea-pig and hamster. In addition to chorioallantoic membrane and rabbit cornea, the virus can be grown on HeLa cells and human amnion.

\section{Pathology}

The histological picture of an herpetic vesicle shows: (a) eosinophilic intranuclear inclusion bodies, (b) multinucleated giant cells, and (c) ballooning degeneration of the epithelial cells. Athough the changes are similar, the lesions on the mucous membranes present as shallow ulcers and rarely as vesicles.

In the central nervous system, herpes simplex virus infection may produce extensive cerebral oedema and necrosis of brain tissue with cavita- 